\title{
Energy Drink Consumption Among Finnish Adolescents: Prevalence, Associated Background Factors, Individual Resources, and Family Factors
}

\author{
Maija Puupponen ${ }^{1 *}$, Jorma Tynjälä ${ }^{1}$, Asko Tolvanen $^{2}$, Raili Välimaa ${ }^{1}$ and Leena Paakkari ${ }^{1}$ \\ ${ }^{1}$ Research Center for Health Promotion, Faculty of Sport and Health Sciences, University of Jyväskylä, Jyväskylä, Finland, \\ ${ }^{2}$ Department of Psychology, Faculty of Education and Psychology, University of Jyväskylä, Jyväskylä, Finland
}

OPEN ACCESS

Edited by:

Jens Bucksch,

Heidelberg University of Education,

Germany

*Correspondence:

Maija Puupponen

maija.puupponen@jyu.fi

Received: 22 October 2020

Accepted: 25 March 2021

Published: 07 May 2021

Citation:

Puupponen M, Tynjälä J, Tolvanen A, Välimaa $R$ and Paakkari L (2021) Energy Drink Consumption Among Finnish Adolescents: Prevalence, Associated Background Factors, Individual Resources, and

Family Factors.

Int J Public Health 66:620268.

doi: 10.3389/ijph.2021.620268
Objectives: Energy drink consumption among adolescents has become a notable global phenomenon, and has been associated with numerous negative health outcomes. In order to understand the popularity of energy drinks among adolescents, and to target interventions, it is important to identify the determinants underpinning consumption.

Methods: The nationally representative data (cross-sectional) were drawn from the Health Behaviour in School-aged Children (HBSC) surveys, conducted in 2014 and 2018, each comprising 13- and 15-year-old Finnish adolescents ( $n=7405)$.

Results: Weekly energy drink consumption increased among Finnish adolescents between 2014 (18.2\%) and 2018 (24.4\%), especially among girls. In 2018, boys typically consumed more than girls, and 15-year-olds more than 13-year-olds. Moreover, in 2018, weekly energy drink consumption was more prevalent among 15-year-old adolescents with a nonacademic educational aspiration (46.0\%) than among adolescents with an academic aspiration (18.3\%). Gender (boys more than girls), older age (only in 2018), less parental monitoring, lower school achievement, and a lower level of health literacy explained around $28 \%$ of the variance in weekly energy drink consumption in both years.

Conclusion: According to the findings, interventions to decrease the energy drink consumption, should be targeted at all adolescents, but especially at those with fewer individual resources. The interventions should also pay attention to family-level factors.

Keywords: energy drinks, adolescents, parental monitoring, school achievement, health literacy, educational aspirations

\section{INTRODUCTION}

Adolescence is a period of rapid physical and psychological changes, and cognitive development [1], within which health-related behaviors begin to form, creating a base for future health [2]. The consumption of caffeine-based and carbonated energy drinks, containing also plant-based stimulants [3] and other ingredients [4], has become a global phenomenon. Their consumption by adolescents has been associated with numerous negative health outcomes, including cardiovascular symptoms [5], psychological symptoms, and headaches [5-7]. National recommendations regarding these beverages have been established in Finland [8], with the aim of limiting their 
consumption among adolescents. These are in line with European recommendations [9], based on the view that the stimulant content is inappropriate for this target group [10]. In Europe mandatory labeling has been established for products with added caffeine content, indicating that the drinks in question are not recommended for children [11].

Energy drinks are widely consumed by adolescents across the world, and adolescents are the main consumers of these beverages [3]. It is difficult to compare the prevalence of consumption among adolescents internationally and across Europe, due to the different methodologies adopted by studies. In a large European study on annual consumption levels, $68 \%$ of adolescents were identified as energy drink consumers on the basis that they had consumed these drinks at least once over the past year [3]. Studies on consumption on a last-three-months basis have produced a figure of $36.4 \%$ of adolescents in the United States [12], while within Europe the figures have ranged from $48 \%$ (Greece) to $82 \%$ (Czech Republic) [3]. The proportion in Finland (65\%) has been reported as in line with the average European level [3]. In studies reporting consumption on a monthly basis, figures such as $52.3 \%$ have been reported in Europe [13]. Miller et al. [12] found the (at least) weekly energy drink consumption of adolescents in the United States to be $15.1 \%$. A weekly figure of $20.6 \%$ was found in Slovakia [14], while in Norway, weekly consumption figures of 15.1-22.4\% have been obtained [13].

The available evidence indicates that among adolescents, higher energy drink consumption is linked to male gender [3, 6, 15-17], and older adolescence $[13,15]$. It has also been linked to rural residency [13], lower socioeconomic status [13, 18], lower school achievement $[17,19,20]$, and lower parental monitoring [21].

More research is needed on the association between energy drink consumption and several other individual resources previously linked to adolescents' health behaviors. These include health literacy (i.e. a set of competencies that enable individuals to make sound health decisions, and to work on and change the factors affecting their own and others' health) [22], and educational aspiration (i.e. plans after basic education), both of which have been linked to substance use (e.g. smoking and alcohol consumption) and oral health [23]. As far as we know, there is only limited research on how these might be associated with the consumption of energy drinks.

To understand the energy drink phenomenon among adolescents, it is important to identify the determinants which underpin it. It may then be possible to target intervention at the appropriate group of adolescents, the aim being to intervene at an early stage, prevent health compromising behaviors, and improve health in adolescence, and later in life [2]. Even though the topic has been raised in national political conversations [24], there is a lack of systematic information on the phenomenon in Finland. To gain a deeper understanding of the relevant factors, and of how consumption is evolving, this study aimed to answer the following questions:

1. How prevalent is energy drink consumption, especially on a weekly basis, among Finnish adolescents, and has there been any change in consumption patterns between 2014 and 2018 (RQ1).

2. Which background factors (gender, age, place of residence, geographical region), individual resources (educational aspiration, school achievement, health literacy), and family factors (parental monitoring, family affluence) are associated with weekly energy drink consumption (RQ2), and has there been any change in the associations between 2014 and 2018? (RQ3).

\section{METHODS}

\section{Data}

The nationally representative data (cross-sectional) were drawn from the Health Behaviour in School-aged Children (HBSC) surveys among Finnish adolescents. Surveys were conducted in 2014 (a paper-and-pen questionnaire) and 2018 (an online questionnaire via Webropol software, Webropol Oy, Helsinki, Finland) during school hours, anonymously. Participation was voluntary. Stratification in the sampling was carried out according to the European Union NUTS classification (Nomenclature of Territorial Units for Statistics). The sampling was based on the Finnish school register. The participating schools were chosen using a random cluster sampling method adjusted for the province, municipality, and school size (PPS, Proportion Probable Size). The participating classes were randomly selected within each school. In 2014, the study obtained ethical approval according to Finnish national guidelines, and in 2018, from the University of Jyväskylä Ethical Committee. The school principals gave the school-level approval. In 2014, parental/guardian consent was obtained in the form of passive consent, i.e. with the option to withdraw the adolescent from participation. In 2018, some schools required active parental/guardian consent.

The total sample consisted of 7405 Finnish adolescents. In 2014 the sample size was 5195, of which $51 \%$ were boys and $49 \%$ were girls. The proportion of 13 -year-olds was $49 \%$, and the proportion of 15 -year-olds was $51 \%$. The sample in 2014 included 184 schools, and the response rate was $86.4 \%$. In 2018 the sample size was 2429 , of which $50.1 \%$ were boys and $49.9 \%$ were girls. The proportion of 13 -year-olds was $51.9 \%$, and the proportion of 15 -year-olds was $48.1 \%$. The sample in 2018 included 77 schools, and the response rate was $54.1 \%$.

\section{Measures}

The background factors used in the analyses comprised gender (boy/girl), age (13- and 15-year-olds), place of residence (dichotomized as urban/rural), geographical region (covering the South-North dimension, and grouped as Capital city area, Southern Finland, Central Finland, and Northern Finland).

The individual resources examined were educational aspiration, school achievement, and health literacy. Educational aspiration was assessed by asking the students to indicate what they would do after the comprehensive school (at age 15). The response categories were: upper secondary school, vocational school or other vocational training, an apprenticeship, double examination (conducted at both upper secondary school and vocational school), get a job, be unemployed, don't know. For the analyses, the responses were recoded into two broad categories covering educational aspiration, i.e. academic aspiration (combining general upper secondary school and double examination), and nonacademic aspiration (combining vocational school and an apprenticeship). Other responses were not included in the analyses due to their low frequency. 
School achievement was measured by asking students to indicate their most recent grade for the first language and for mathematics. The grade for these two subjects were ranked from lowest to highest (grades 4-10) and computed. The mean values of the grades were recoded into three categories, i.e. low (grades 4-6.5), medium (grades 7-8.5), and high (grades 9-10) school achievement.

Health literacy (as a set of competencies to make health decisions and to identify and modify the factors that affect health) was measured by an instrument (HLSAC) created specifically for adolescents $[25,26]$. The instrument was computed from 10 different items. Each item began with: "I am confident that...". The response options were: "not at all true," "barely true," "somewhat true," and "absolutely true." The responses were computed and recoded as three categories, in line with Paakkari et al. [27]: low (values 10-25), medium (values 26-35), and high (values 36-40) health literacy.

The family factors assessed were family affluence and parental monitoring. The self-reported 'relative socioeconomic position of the family' (the family's material resources, patterns of consumption, and purchasing power) was assessed via the Family Affluence Scale III (FASIII) [28]. FASIII includes six items: ownership of a car, having one's own bedroom, number of family computers, number of bathrooms, ownership of a dishwasher at home, number of family holidays during the past 12 months. The computed scores were recoded using three categories, in line with the HBSC protocol [29]: low (lowest 20\%), medium (middle 60\%), and high (highest 20\%) family affluence.

Parental monitoring was measured by an instrument of Brown et al. [30], using questions starting with: "How much does your mother/father know about ...”. The instrument was computed from five items, relating to who your friends are, how you spend your money, where you are after school, where you go at night, what you do during your free time. The response options were: "don't have or don't meet," "doesn't know anything," "knows a little," and "knows a lot." The mean values were recoded into three categories: low (lowest 33.3\%), medium (middle 33.3\%), and high (highest $33.3 \%$ ) parental monitoring.

Energy drink consumption was measured by asking "How often do you eat or drink the following?," with energy drinks forming one option in a 5 -item set. The response options were: "never," "less than once a week," "once a week," "2-4 days a week," "5-6 days a week," "once a day, every day," and "every day, more than once." The responses were regrouped into three categories: weekly consumption, less than weekly consumption, and no consumption. For the regression analyses, the responses were also dichotomized as two categories, i.e. as weekly and less than weekly/no consumption, in line with the European Food Safety Authority categories [3], and with previous studies [15, 17, 31 ], on the rationale that weekly energy drink consumption indicates more regular consumption of energy drinks.

\section{Statistical Analyses}

Due to the nested structure of data (with pupils nested in classrooms), descriptive analysis and multilevel mixed-effects binary logistic regression analysis was executed using the Stata (version 16) procedures for complex survey design. The sample design allowed to obtain precise confidence intervals (CIs) for proportions and odds ratios. The variance proportion coefficients (VPCs) were calculated for both age groups via multilevel mixed-effects binary logistic regression analyses, making it possible to measure the school effect. Mplus (version 8.0) with complex methods and the WLSMV estimator was used to obtain the standardized regression coefficients and unbiased standard errors. This method corrects the bias of standard errors due the school effect. Note that because the proportion of Swedish-speaking students in the data was larger than in the general population, all the analyses were weighted accordingly. Moreover, the analyses were weighted for grade in both survey years.

\section{RESULTS}

\section{Prevalence of Energy Drink Consumption, and Distribution of Consumption by Background Factors, Individual Resources and Family Factors (RQ1)}

As shown in the Table 1, weekly energy drink consumption increased among Finnish adolescents between 2014 (18.2\%) and 2018 (24.4\%). More specifically, the weekly consumption increased among girls (from $9.4 \%$ to $16.8 \%$ ), and among 15 year-olds (from $19.4 \%$ to $28.2 \%$ ). The proportion of adolescents not consuming energy drinks decreased between 2014 (54.8\%) and $2018(49.6 \%)$.

In 2018, half of the adolescents reported consumption of energy drinks (combining weekly and less than weekly consumption). A quarter of the adolescents reported consumption of energy drinks on a weekly basis, boys (32.1\%) more typically than girls (16.8\%), and 15-yearolds (28.2\%) more typically than 13-year-olds (20.6\%). Less than weekly consumption was as prevalent as weekly consumption among 13- and 15-year-olds, and among boys, but not among girls. Half of the adolescents did not consume energy drinks at all. The proportion of adolescents not consuming energy drinks was higher among girls (58.9\%) than boys (40.4\%), and among 13-year-olds (56.2\%) than 15year-olds $(43.1 \%)$.

Table 1 indicates that in both survey years, weekly energy drink consumption was more prevalent when scores for parental monitoring, school achievement, and health literacy were low. As regards geographical regions, the increase in energy drink consumption between 2014 and 2018 was statistically significant only in Southern Finland (from 18.5\% to $23.8 \%$ ) and in Northern Finland (from $16.9 \%$ to $31.0 \%$ ). Furthermore, in both survey years, weekly energy drink consumption was more prevalent among adolescents with a non-academic educational aspiration (increasing from $30.6 \%$ to $46.0 \%$ ) than among adolescents with an academic aspiration (increasing from $11.1 \%$ to $18.3 \%$ ). 
TABLE 1 | The prevalence of energy drink consumption and the distribution of consumption, by background factors, individual resources and family factors (Health Behaviour in School-aged Children, Finland, 2014 and 2018).

\begin{tabular}{|c|c|c|c|c|c|c|c|c|c|c|c|}
\hline & \multicolumn{5}{|c|}{2014} & \multicolumn{5}{|c|}{2018} & \multirow[b]{2}{*}{$\begin{array}{c}2014 \\
\text { vs. } \\
2018 \\
p \text { value }\end{array}$} \\
\hline & $\begin{array}{c}\text { Weekly } \\
\text { energy } \\
\text { drink } \\
\text { consumption }\end{array}$ & $\begin{array}{c}\text { Less } \\
\text { than } \\
\text { weekly } \\
\text { energy } \\
\text { drink } \\
\text { consumption }\end{array}$ & $\begin{array}{l}\text { No energy } \\
\text { drink } \\
\text { consumption }\end{array}$ & $\begin{array}{l}\text { Total } \\
\%(n)\end{array}$ & $\begin{array}{c}2014 \\
p \text { value }\end{array}$ & $\begin{array}{c}\text { Weekly } \\
\text { energy } \\
\text { drink } \\
\text { consumption }\end{array}$ & $\begin{array}{l}\text { Less } \\
\text { than } \\
\text { weekly } \\
\text { energy } \\
\text { drink } \\
\text { consumption }\end{array}$ & $\begin{array}{l}\text { No energy } \\
\text { drink } \\
\text { consumption }\end{array}$ & $\begin{array}{l}\text { Total } \\
\%(n)\end{array}$ & $\begin{array}{c}2018 \\
p \text { value }\end{array}$ & \\
\hline Gender & & & & & $<0.001$ & & & & & $<0.001$ & \\
\hline Boys & 27.2 [24.8-29.7] & $32.3[30.1-34.6]$ & 40.5 [37.9-43.2] & $100(2460)$ & & $32.1[28.7-35.7]$ & $27.5[24.8-30.5]$ & $40.4[36.7-44.1]$ & 100 (1203) & & 0.02 \\
\hline Girls & $9.4[8.1-10.9]$ & 21.8 [19.8-23.9] & 68.9 [66.4-71.2] & 100 (2496) & & $16.8[14.2-19.7]$ & $24.4[21.2-27.9]$ & $58.9[54.5-63.1]$ & 100 (1203) & & $<0.001$ \\
\hline All & $18.2[16.7-19.8]$ & $27.0[25.4-28.6]$ & $54.8[52.8-56.8]$ & 100 (4956) & & $24.4[22.2-26.7]$ & 26.0 [23.8-28.2] & $49.6[46.7-52.6]$ & 100 (2406) & & $<0.001$ \\
\hline Age & & & & & $<0.01$ & & & & & $<0.001$ & \\
\hline 13-year-olds & $17.0[14.9-19.4]$ & $24.7[22.5-27.1]$ & $58.3[55.4-61.1]$ & $100(2487)$ & & 20.6 [17.5-24.0] & 23.2 [20.6-26.1] & 56.2 [51.8-60.6] & 100 (1239) & & 0.16 \\
\hline 15-year-olds & $19.4[17.3-21.6]$ & $29.2[27.0-31.5]$ & $51.4[48.6-51.2]$ & 100 (2469) & & $28.2[25.1-31.5]$ & $28.7[26.0-31.6]$ & $43.1[39.8-46.5]$ & 100 (1167) & & $<0.001$ \\
\hline Family affluence & & & & & 0.28 & & & & & 0.28 & \\
\hline Low & 19.6 [16.5-23.2] & 28.9 [25.2-33.0] & $51.5[47.0-55.9]$ & $100(561)$ & & $26.1[21.3-31.7]$ & 26.6 [21.6-32.3] & $47.3[41.2-53.4]$ & 100 (229) & & 0.12 \\
\hline Medium & $17.6[15.9-19.4]$ & $27.5[25.5-29.6]$ & $54.9[52.6-57.2]$ & $100(2701)$ & & $25.0[22.1-28.0]$ & $25.6[22.7-28.8]$ & $49.4[45.6-53.3]$ & $100(1218)$ & & $<0.001$ \\
\hline High & $17.5[15.2-20.1]$ & $25.5[23.0-28.3]$ & $57.0[53.5-60.3]$ & $100(1515)$ & & $21.1[17.9-24.6]$ & $27.1[23.9-30.5]$ & $51.9[47.8-55.9]$ & 100 (842) & & 0.10 \\
\hline Parental monitoring & & & & & $<0.001$ & & & & & $<0.001$ & \\
\hline Low & 29.4 [26.5-32.5] & 32.6 [29.8-35.5] & $38.0[35.1-40.9]$ & 100 (1489) & & $41.1[36.2-46.3]$ & $28.8[25.0-32.9]$ & $30.1[25.8-34.8]$ & $100(674)$ & & $<0.001$ \\
\hline Medium & $13.8[12.2-15.6]$ & $27.9[25.7-30.2]$ & $58.3[55.8-60.7]$ & 100 (1939) & & $18.6[15.7-21.9]$ & $27.0[23.4-30.9]$ & 54.4 [49.3-59.3] & $100(838)$ & & 0.04 \\
\hline High & $11.0[9.2-13.1]$ & 20.4 [18.0-22.9] & $68.6[65.6-71.6]$ & $100(1456)$ & & $13.0[10.7-15.7]$ & $23.2[20.5-26.1]$ & $63.8[60.2-67.3]$ & $100(804)$ & & 0.11 \\
\hline Place of residence & & & & & 0.47 & & & & & 0.98 & \\
\hline Urban & $17.8[16.0-19.8]$ & 26.5 [24.6-28.6] & $55.7[53.1-58.3]$ & $100(2978)$ & & $24.5[21.8-27.5]$ & 25.7 [22.9-28.7] & 49.8 [46.2-53.3] & 100 (1254) & & $<0.001$ \\
\hline Rural & $18.7[16.4-21.2]$ & $27.9[25.4-30.6]$ & $53.4[50.3-56.4]$ & 100 (1942) & & $24.3[21.7-27.9]$ & 26.2 [23.1-29.5] & $49.5[45.0-54.0]$ & 100 (1145) & & 0.03 \\
\hline Geographical region & & & & & $<0.01$ & & & & & 0.03 & \\
\hline Capital city area & $14.5[10.1-20.4]$ & $20.5[16.3-25.4]$ & 65.0 [58.0-71.5] & 100 (711) & & 20.9 [15.3-27.9] & 19.8 [14.3-26.7] & $59.3[51.0-67.1]$ & $100(248)$ & & 0.25 \\
\hline Southern Finland & $18.5[16.1-21.1]$ & $25.6[23.3-28.1]$ & $55.9[52.6-59.1]$ & $100(1674)$ & & $23.8[21.1-26.6]$ & $26.6[23.4-30.1]$ & $49.6[45.0-54.3]$ & $100(1077)$ & & 0.02 \\
\hline Central Finland & $20.0[17.6-22.5]$ & $28.6[25.9-31.4]$ & $51.5[48.4-54.6]$ & 100 (1785) & & $24.4[19.8-29.8]$ & $26.8[23.2-30.7]$ & $48.8[44.0-53.6]$ & $100(784)$ & & 0.20 \\
\hline Northern Finland & $16.9[13.1-21.6]$ & $31.6[27.5-36.0]$ & $51.5[46.6-56.4]$ & $100(703)$ & & $31.0[25.5-37.1]$ & $28.1[23.0-33.7]$ & 40.9 [36.6-45.4] & 100 (276) & & $<0.001$ \\
\hline $\begin{array}{l}\text { Educational aspiration } \\
\text { (15-year-olds) }\end{array}$ & & & & & $<0.001$ & & & & & $<0.001$ & \\
\hline Academic & $11.1[9.8-12.5]$ & $24.0[22.1-26.0]$ & $64.9[62.6-67.1]$ & 100 (2997) & & $18.3[15.5-21.4]$ & 30.3 [27.0-33.9] & $51.4[47.3-55.4]$ & $100(746)$ & & $<0.001$ \\
\hline Non-academic & $30.6[27.6-33.8]$ & $34.0[31.4-36.8]$ & $35.4[32.5-38.4]$ & $100(1501)$ & & $46.0[40.8-51.4]$ & 26.2 [21.9-30.9] & $27.8[23.4-32.7]$ & 100 (389) & & $<0.001$ \\
\hline School achievement & & & & & $<0.001$ & & & & & $<0.001$ & \\
\hline Low & 38.9 [34.8-43.2] & 31.9 [28.3-35.7] & 29.3 [25.7-33.2] & 100 (733) & & $53.4[48.4-58.4]$ & 24.3 [20.3-28.8] & $22.3[18.3-26.8]$ & $100(368)$ & & $<0.001$ \\
\hline Medium & 18.4 [16.6-20.3] & $29.0[27.0-31.0]$ & $52.7[50.4-54.9]$ & 100 (2963) & & 23.1 [20.5-26.0] & $29.0[26.5-31.6]$ & $47.9[44.5-51.3]$ & 100 (1346) & & $<0.01$ \\
\hline High & $5.6[4.3-7.3]$ & $19.2[16.9-21.9]$ & 75.2 [72.2-78.0] & 100 (1225) & & $11.0[8.6-14.1]$ & $21.0[17.2-25.5]$ & $67.9[63.1-72.4]$ & $100(628)$ & & $<0.01$ \\
\hline Health literacy & & & & & $<0.001$ & & & & & $<0.001$ & \\
\hline Low & 32.4 [27.8-37.4] & 30.5 [26.1-35.3] & 37.1 [32.0-42.5] & 100 (431) & & $42.9[36.2-49.7]$ & $25.3[19.0-32.8]$ & 31.9 [25.1-39.5] & $100(208)$ & & 0.07 \\
\hline Medium & $17.6[15.8-19.4]$ & 28.9 [26.9-31.0] & $53.5[51.1-55.9]$ & $100(2650)$ & & $24.4[21.2-27.8]$ & 26.2 [23.5-29.2] & $49.5[45.4-53.3]$ & 100 (1239) & & $<0.001$ \\
\hline High & $12.8[11.0-14.8]$ & $23.2[21.0-25.8]$ & $64.0[61.1-66.8]$ & $100(1552)$ & & $17.3[14.9-20.1]$ & 26.7 [23.4-30.2] & $56.0[52.2-59.7]$ & 100 (783) & & $<0.01$ \\
\hline
\end{tabular}


TABLE 2 | Multilevel mixed-effects binary logistic regression on the associations between weekly energy drink consumption and background factors, individual resources and family factors, among 13- and 15-year-olds (Health Behaviour in School-aged Children, Finland, 2014 and 2018 ).

\begin{tabular}{|c|c|c|c|c|c|c|c|}
\hline & & \multicolumn{3}{|c|}{ Model 1 (13-year-olds $\left.{ }^{a}\right) n=3217$} & \multicolumn{3}{|c|}{ Model 2 (15-year-olds $\left.{ }^{b}\right) n=3197$} \\
\hline & & OR & $95 \% \mathrm{Cl}$ & $p$ & OR & $95 \% \mathrm{Cl}$ & $p$ \\
\hline \multirow[t]{2}{*}{ Gender } & Girl & 1.00 & & & 1.00 & & \\
\hline & Boy & 2.39 & {$[1.91-2.98]$} & $<0.001$ & 2.71 & [2.21-3.32] & $<0.001$ \\
\hline \multirow[t]{2}{*}{ Survey year } & 2014 & 1.00 & & & 1.00 & & \\
\hline & 2018 & 1.54 & [1.13-2.09] & $<0.01$ & 1.93 & [1.56-2.39] & $<0.001$ \\
\hline \multirow[t]{2}{*}{ Place of residence } & Urban & 1.00 & & & 1.00 & & \\
\hline & Rural & 1.04 & [0.81-1.33] & 0.79 & 0.99 & {$[0.81-1.24]$} & 0.99 \\
\hline \multirow[t]{4}{*}{ Geographical region } & Capital city area & 1.00 & & & 1.00 & & \\
\hline & Southern Finland & 1.39 & [0.87-2.23] & 0.17 & 0.85 & {$[0.60-1.21]$} & 0.38 \\
\hline & Central Finland & 1.67 & [1.04-2.68] & 0.04 & 1.12 & [0.78-1.61] & 0.54 \\
\hline & Northern Finland & 1.71 & [0.98-2.98] & 0.06 & 1.08 & [0.70-1.65] & 0.74 \\
\hline \multirow[t]{3}{*}{ Family affluence } & High & 1.00 & & & 1.00 & & \\
\hline & Medium & 0.83 & [0.65-1.05] & 0.11 & 0.79 & [0.64-0.98] & 0.04 \\
\hline & Low & 0.85 & [0.59-1.23] & 0.40 & 0.72 & [0.51-1.02] & 0.07 \\
\hline \multirow[t]{3}{*}{ Parental monitoring } & High & 1.00 & & & 1.00 & & \\
\hline & Medium & 1.65 & [1.22-2.22] & $<0.01$ & 1.26 & [0.98-1.63] & 0.07 \\
\hline & Low & 5.71 & {$[4.25-7.67]$} & $<0.001$ & 2.24 & {$[1.75-2.88]$} & $<0.001$ \\
\hline \multirow[t]{3}{*}{ School achievement } & High & 1.00 & & & 1.00 & & \\
\hline & Medium & 2.71 & [1.96-3.75] & $<0.001$ & 2.57 & [1.87-3.53] & $<0.001$ \\
\hline & Low & 5.46 & {$[3.66-8.16]$} & $<0.001$ & 4.58 & [3.13-6.71] & $<0.001$ \\
\hline \multirow[t]{3}{*}{ Health literacy } & High & 1.00 & & & 1.00 & & \\
\hline & Medium & 1.07 & [0.82-1.39] & 0.63 & 1.26 & [1.01-1.56] & 0.04 \\
\hline & Low & 1.75 & [1.22-2.49] & $<0.01$ & 1.52 & [1.07-2.16] & 0.02 \\
\hline \multirow[t]{2}{*}{ Educational aspiration $^{c}$} & Academic & & & & 1.00 & & \\
\hline & Non-academic & & & & 1.88 & [1.50-2.36] & $<0.001$ \\
\hline
\end{tabular}

OR, odds ratio; $\mathrm{Cl}$, confidence interval.

${ }^{a}$ School effect $\mathrm{p}<0.001$, variance proportion coefficient: 0.118 .

${ }^{b}$ School effect $\mathrm{p}=0.12$, variance proportion coefficient: 0.0169 .

cIn both 2014 and 2018, educational aspiration was included in the survey only for 15-year-olds.

TABLE 3 | Linear regression model on the strength of the associations between weekly energy drink consumption and gender, age, parental monitoring, school achievement, and health literacy, separately by year (Health Behaviour in School-aged Children, Finland, 2014 and 2018).

\begin{tabular}{|c|c|c|c|c|c|c|}
\hline & \multicolumn{3}{|c|}{2014} & \multicolumn{3}{|c|}{2018} \\
\hline & \multicolumn{3}{|c|}{$R^{2}=0.28, p$ value $<0.001(n=4592)$} & \multicolumn{3}{|c|}{$R^{2}=0.28, p$ value $<0.001(n=2170)$} \\
\hline & $\beta$ & $95 \% \mathrm{Cl}$ & $p$ value & $\beta$ & $95 \% \mathrm{Cl}$ & $p$ value \\
\hline Gender & $-0.256^{\mathrm{a}}$ & {$[-0.302--0.211]$} & $<0.001$ & $-0.145^{\mathrm{a}}$ & {$[-0.212--0.078]$} & $<0.001$ \\
\hline Age & $0.019^{b}$ & {$[-0.032-0.071]$} & 0.47 & $0.108^{b}$ & {$[0.044-0.171]$} & $<0.01$ \\
\hline Parental monitoring & $-0.243^{c}$ & {$[-0.287--0.198]$} & $<0.001$ & $-0.258^{\mathrm{C}}$ & {$[-0.321--0.196]$} & $<0.001$ \\
\hline School achievement & $-0.249^{d}$ & {$[-0.291--0.207]$} & $<0.001$ & $-0.286^{\mathrm{d}}$ & {$[-0.348--0.225]$} & $<0.001$ \\
\hline Health literacy & $-0.071^{e}$ & {$[-0.110--0.033]$} & $<0.001$ & $-0.111^{\mathrm{e}}$ & {$[-0.161--0.062]$} & $<0.001$ \\
\hline
\end{tabular}

${ }^{a}$ For girls.

${ }^{b}$ For 15-year-olds.

${ }^{c-e}$ The greater the value below zero, the higher the level of the selected variable.

\section{Associations Between Weekly Energy Drink Consumption and Background Factors, Individual Resources and Family Factors (RQ2) in 2014 and 2018 (RQ3)}

Among 13-year-olds, weekly energy drink consumers were more likely to be a boy, live in Central Finland, report medium or low parental monitoring, report medium or low school achievement, and report low health literacy (Table 2). Among 13-year-olds, the inter-school variance (variance partition coefficient, VPC) was $11.8 \%$ of the total variance.
Among 15-year-olds, weekly energy drink consumers were more likely to be a boy, report low parental monitoring, report medium or low school achievement, report medium or low health literacy, and report non-academic aspiration. By contrast, adolescents reporting medium family affluence were less likely to consume energy drinks on a weekly basis.

These associations were further confirmed via the linear regression model (Table 3 ). On the basis of the results of logistic regression analysis, gender, age, parental monitoring, school achievement, and health literacy were chosen to predict the weekly energy drink consumption. Educational aspiration 
was not included in the model, in order to include both age groups in the model.

Overall, the chosen factors showed medium effect sizes [32], explaining 28\% of weekly energy drink consumption in 2014 and in 2018. When all the factors were analyzed simultaneously, gender (boys more than girls), less parental monitoring, lower school achievement, and a lower level of health literacy, explained the variance in weekly energy drink consumption in both years. Age (greater consumption among 15-year-olds than 13-yearolds) explained the variance only in 2018.

According to the confidence intervals of the regression coefficients, gender, parental monitoring, school achievement, and health literacy were equally strongly associated with weekly energy drink consumption in both 2014 and 2018.

\section{DISCUSSION}

According to our study, in 2018 every second Finnish adolescent reported consumption of energy drinks, and every fourth adolescent reported consumption on a weekly basis. Variation emerged according to background factors, individual resources, and family factors. Weekly consumption increased from 2014 to 2018 , suggesting that energy drinks have not lost their popularity among Finnish adolescents, despite the fact that these beverages are inappropriate for this target group [9-11]. It should nevertheless be noted that the increase in consumption is inconsistent with some recent international findings [33]. Our results indicate that in 2018 energy drink consumption was more common among older adolescents, confirming previous findings $[13,15]$. Longitudinal research is needed to explore, whether the consumption of these beverages is merely an experimental or passing phase in adolescence, or rather a phenomenon that increases during adolescence.

Energy drink consumption and the advertising related to it, has traditionally been linked to masculinity norms [12]. However, more recent evidence has indicated that the marketing of these beverages has changed, and that adolescents themselves have the impression that specific drinks are targeted at either male or female consumers [34]. The selection of energy drinks has increased, with options differing by package and overall image. Indeed, as our results indicate, girls' weekly consumption has increased considerably, raising the possibility that the gender normative trend of specific health behaviors has started to change. This despite the fact that boys consume energy drinks more than girls $[3,6,15-17]$, a finding confirmed also by this study. The popularity of these drinks among boys, has been explained via the fact that energy drink consumption is linked to screen time [35] and to gaming [31], both of which are higher among boys.

Health behaviors track forward to adulthood, calling for a deeper understanding not only of the individuals' background factors reflected above, but also of individual resources, and of family factors, as these all affect this specific health behavior. It has been reported that adolescents have limited knowledge of the ingredients of energy drinks, especially of their key ingredient, i.e. caffeine $[16,36]$, and that they tend to confuse them with sports drinks [36] or with other soft drinks [16, 31, 36]. Moreover, weekly energy drink consumption has been associated with adolescents' perceptions that energy drinks are safe drinks for teens [37]. As our study indicates, weekly energy drink consumption was associated with low and medium health literacy, confirming the need to undertake targeted interventions and to develop adolescents' knowledge and skills related to energy drinks.

Besides lower levels of health literacy, the weekly consumption of energy drinks was found to be more likely among adolescents with lower academic achievement, consistent with the notion that current school achievement is an important indicator of the level of health and health behavior (see also [17, 19, 20]). Moreover, our study indicated that weekly energy drink consumption was more prevalent among adolescents with non-academic educational plans. There is clear evidence on health and health behavior differences between persons with academic and nonacademic aspirations, providing a rough indication of adolescents' future social position and health inequalities [38]. It has been reported that students following the non-academic path have more health compromising behaviors than students following the academic path [38, 39]. Within Finland, students in vocational schools consume energy drinks to a considerably greater extent than students in general upper secondary schools [40].

Interestingly, family affluence, which is typically seen as a strong predictor of health behaviors [41], had no significant role in energy drink consumption in the sample as a whole; nevertheless, a weak association was found when age-specific consumption was examined. Among 15-year-olds, those reporting medium level family affluence were less likely to consume energy drinks weekly than those reporting high family affluence. This contrasts with the study by Degirmenci et al. [13] who found that lower socioeconomic status is associated with higher energy drink consumption. At the same time, it has been reported that higher parental monitoring is associated with a lowered risk of health compromising behaviors [42] including energy drink consumption [21]. In line with this, we found that the more parents knew about their child's free time activities, their company, and their money expenditure, the less likely it was that adolescent consumed energy drinks weekly - a finding underlining the role of parents in the consumption of these drinks.

In the lives of adolescents, an important source of information on energy drinks could potentially be family members, who may well consume energy drinks themselves [36]. It is therefore important also to ensure that information reaches the home, so that parents have a good level of knowledge on energy drink constituents and on their possible effects among adolescents. In some existing studies, parents' actions have actually been seen to increase energy drink consumption, insofar as they purchase them for the adolescents and encourage adolescents to drink them, in order to decrease fatigue or improve sports performance [36].

Our findings indicate that in seeking to decrease weekly energy drink consumption, certain factors should be examined in more detail. It was notable that factors such as gender, age (only in 2018), school achievement, parental monitoring, and health 
literacy explained almost $30 \%$ of the variation in weekly energy drink consumption, in both 2014 and 2018. The percentages are striking, given that (apart from gender) several of these factors are modifiable. It seems that if one is aiming to influence health disparities among adolescents, interventions should be targeted at all adolescents, but especially at those with fewer individual resources. In addition, the interventions should pay attention to family-level factors.

Among the strengths of the current study, one can number valid measures, a large, nationally representative database, and two separate survey years. The study provided important information on energy drink consumption in Finland. However, due to the cross-sectional study design, it is not possible to make causal inferences between consumption and the measured individual determinants. In addition, the survey relied on self-reports, so assessment of energy drink consumption was subject to self-reporting bias. The current survey did not include the precise quantity of energy drinks consumed over a certain period of time; hence, the quantity of energy drinks consumed at a given time remains unclear. Note also that in this study energy drink consumption was studied separately from other habits. Further research is needed to examine energy consumption together with other health habits and contextual factors (e.g. peers and family) to build a coherent understanding of the phenomenon.

\section{CONCLUSION}

Energy drink consumption, especially on a weekly basis, increased among Finnish adolescents between 2014 and 2018, and among girls in particular. The findings suggest that special attention should be paid to those adolescents who aim at a non-academic education, or who have lower school achievement or a lower level of health literacy. It is important to understand the significant role that school and health education could play in decreasing the consumption of energy drinks, for instance by developing the health literacy of adolescents. Furthermore, we suggest that parental monitoring of friends, expenditure, and free time activities may be important as a preventive factor.

\section{REFERENCES}

1. Borzekowski, DLG. Considering children and health literacy: a theoretical approach. Pediatrics (2009) 124:S282-S288. doi:10.1542/peds.2009-1162D

2. Sawyer, SM, Afifi, RA, Bearinger, LH, Blakemore, S-J, Dick, B, Ezeh, AC, et al. Adolescence: a foundation for future health. The Lancet (2012) 379:1630-40. doi:10.1016/S0140-6736(12)60072-5

3. Zucconi, S, Volpato, C, Adinolfi, F, Gandini, E, Gentile, E, Loi, A, et al. Gathering consumption data on specific consumer groups of energy drinks. EFSA European Food safety authority. (2013) 10(3). (Accessed June 3, 2020). doi:10.2903/sp.efsa. 2013.EN-394

4. EFSA. Scientific opinion on the safety of caffeine. EFSA panel on dietetic products, nutrition and allergies. European food safety authority. EFSA J (2015) 13(5):4102. doi:10.2903/j.efsa.2015.4102

5. Bashir, D, Reed-Schrader, E, Olympia, RP, Brady, J, Rivera, R, Serra, T, et al. Clinical symptoms and adverse effects associated with energy drink

\section{DATA AVAILABILITY STATEMENT}

The data analyzed in this study is subject to the following licenses/ restrictions: The HBSC Data Management Centre distributes data in accordance with the HBSC data access policy. Requests to access these datasets should be directed to dmc@hbsc.org.

\section{ETHICS STATEMENT}

The studies involving human participants were reviewed and approved by the University of Jyväskylä Ethical Committee regarding the 2018 study, and in 2014, the study obtained ethical approval according to Finnish national guidelines. In accordance with the national legislation and the institutional requirements, in 2014, a consent of participants' legal guardian/ next of kin was obtained in the form of passive consent, and in 2018, some schools required an active guardian consent.

\section{AUTHOR CONTRIBUTIONS}

MP is the principal investigator of this study. MP, JT, RV and LP contributed to the design of the study and the manuscript. MP performed and JT and AT contributed to the statistical analyses. MP wrote the first draft of the manuscript. All authors contributed to the manuscript revision, read, and approved the submitted version.

\section{FUNDING}

This publication was funded by the University of Jyväskylä, Faculty of Sport and Health Sciences.

\section{CONFLICT OF INTEREST}

The authors declare that the research was conducted in the absence of any commercial or financial relationships that could be construed as a potential conflict of interest.

consumption in adolescents. Pediatr Emerg Care (2016) 32(11):751-5 doi:10.1097/PEC.0000000000000703

6. Huhtinen, $H$, and Rimpelä, A. Nuorison energiajuomien käyttö ja kofeiiniin liittyvät oireet [Energy drink consumption and caffeine-induced health complaints in adolescents] Nuorten terveystapatutkimus. Suomen Lääkärilehti [Finnish Med Journal] (2013) 68(39):2451-5.

7. Koivusilta, L, Kuoppamäki, H, and Rimpelä, A. Energy drink consumption, health complaints and late bedtime among young adolescents. Int J Public Health (2016) 61(3):299-306. https://www.laakarilehti.fi/pdf/2013/SLL392013-2451.pdf (Accessed February 20, 2020). doi:10.1007/s00038-016-0797-9

8. Finnish Food Authority. Beverage recommendations for children and young persons (2018) Available from: https://www.ruokavirasto.fi/en/themes/healthydiet/food-groups/beverages/ (Accessed May 15, 2020).

9. SCF. EU Scientific Committee on Food. Opinion of the scientific committee on Food on additional information on "energy" drinks (2003) Available from https://ec.europa.eu/food/sites/food/files/safety/docs/sci-com_scf_out169_en. pdf (Accessed May 15, 2020). 
10. AAP. Sports drinks and energy drinks for children and adolescents: are they appropriate? Committee on nutrition and the council on sports medicine and fitness. Pediatrics (2011) 127:1182. (Accessed May 6, 2020). doi:10.1542/peds. 2011-0965

11. EU. Regulation (EU). No 1169/2011 of the European parliament and of the council of 25 october 2011. Official journal of European union (2011) Available from: https://eur-lex.europa.eu/legal-content/EN/TXT/PDF/?uri=CELEX: 32011R1169\&from=EN (Accessed April 10, 2020).

12. Miller, KE, Dermen, KH, and Lucke, JF. Caffeinated energy drink use by U.S. Adolescents aged 13-17: a national profile. Psychol Addict Behaviors (2018) 32(6):647-59. doi:10.1037/adb0000389

13. Degirmenci, N, Fossum, IN, Strand, TA, Vaktskjold, A, and Holten-Andersen, MN. Consumption of energy drinks among adolescents in Norway: a crosssectional study. BMC Public Health (2018) 18(1):1391. (Accessed July 16, 2020). doi:10.1186/s12889-018-6236-5

14. Holubcikova, J, Kolarcik, P, Madarasova Geckova, A, Reijneveld, SA, and van Dijk, JP. Regular energy drink consumption is associated with the risk of health and behavioural problems in adolescents. Eur J Pediatr (2017) 176(5):599-605. doi:10.1007/s00431-017-2881-4

15. Gallimberti, L, Buja, A, Chindamo, S, Vinelli, A, Lazzarin, G, Terraneo, A, et al. Energy drink consumption in children and early adolescents. Eur J Pediatr (2013) 172(10):1335-40. doi:10.1007/s00431-013-2036-1

16. Musaiger, A, and Zagzoog, N. Knowledge, attitudes and practices toward energy drinks among adolescents in Saudi arabia. Glob J Health Sci (2014) 6(2): 42-6. doi:10.5539/gjhs.v6n2p42

17. Barrense-Dias, Y, Berchtold, A, Akre, C, and Surís, J-C. Consuming energy drinks at the age of 14 predicted legal and illegal substance use at 16. Acta Paediatr (2016) 105(11):1361-8. doi:10.1111/apa.13543

18. Frayon, S, Wattelez, G, Cherrier, S, Cavaloc, Y, Lerrant, Y, and Galy, O. Energy drink consumption in a pluri-ethnic population of adolescents in the Pacific. PLoS ONE (2019) 14(3):e0214420. doi:10.1371/journal.pone.0214420

19. Kim, SY, Sim, S, and Choi, HG. High stress, lack of sleep, low school performance, and suicide attempts are associated with high energy drink intake in adolescents. PLoSONE (2017) 12(11):e0187759. doi:10.1371/journal.pone.0187759

20. Smith, AP, and Richards, G. Energy drinks, caffeine, junk food, breakfast, depression and academic attainment of secondary school students. J Psychopharmacol (2018) 32(8):893-9. doi:10.1177/0269881118783314

21. Miyake, ER, and Marmorstein, NR. Energy drink consumption and later alcohol use among early adolescents. Addict Behaviors (2015) 43:60-5. doi:10. 1016/j.addbeh.2014.12.009

22. Paakkari, $\mathrm{L}$, and Paakkari, O. Health literacy as a learning outcome in schools. Health Educ (2012) 112(2):133-52. doi:10.1108/09654281211203411

23. Paakkari, LT, Torppa, MP, Paakkari, O-P, Välimaa, RS, Ojala, KSA, and Tynjälä, JA. Does health literacy explain the link between structural stratifiers and adolescent health? Eur J Public Health (2019) 29(5):919-24. doi:10.1093/eurpub/ckz011

24. Kuusipalo, H, and Raulio, S. Energiajuomat ja lasten terveys. Onko laille myyntikiellosta perusteita? [Energy drinks and adolescents' health. Should the sale of energy drinks be prohibited?] THL Selvitys. [Finnish Institute for Health and Welfare Statement]. (2018) Available from: https://thl.fi/documents/10531/ 2671150/katsaus_energiajuomien_terveysvaikutuksista.pdf/f086a625-880541f5-bdec-c8b731146dc7 (Accessed December 10, 2019).

25. Paakkari, O, Torppa, M, Kannas, L, and Paakkari, L. Subjective health literacy: development of a brief instrument for school-aged children. Scand J Public Health (2016) 44(8):751-7. doi:10.1177/1403494816669639

26. Paakkari, O, Torppa, M, Boberova, Z, Välimaa, R, Maier, G, Mazur, J, et al. The cross-national measurement invariance of the health literacy for school-aged children (HLSAC) instrument. Eur J Public Health (2019) 29(3):432-6. doi:10. 1093/eurpub/cky229

27. Paakkari, O, Torppa, M, Villberg, J, Kannas, L, and Paakkari, L. Subjective health literacy among school-aged children. Health Educ (2018) 118:182-95. doi:10.1108/HE-02-2017-0014

28. Hartley, JEK, Levin, K, and Currie, C. A new version of the HBSC family affluence Scale - fas III: scottish qualitative findings from the international FAS development study. Child Ind Res (2016) 9:233-45. doi:10.1007/s12187-015-9325-3
29. Currie, D, Elgar, F, Augustson, L, Torsheim, T, and Inchley, J. Key data. In: D. Currie, T. Young, O. Samdal, T. Torsheim, L. Augustson, F. Mathison, et al. editors. Growing up unequal: gender and socioeconomic differences in young people's health and well-being. Health behaviour in school-aged children (HBSC) study: international report from the 2013/2014 survey. Copenhagen: WHO (2016) Available from: https://www.euro.who.int/_data/assets/pdf_ file/0003/303438/HSBC-No.7-Growing-up-unequal-Full-Report.pdf (Accessed December 10, 2019).

30. Brown, BB, Mounts, N, Lamborn, SD, and Steinberg, L. Parenting practices and peer group affiliation in adolescence. Child Develop (1993) 64:467-82. doi:10.1111/j.1467-8624.1993.tb02922.x10.2307/1131263

31. Larson, N, DeWolfe, J, Story, M, and Neumark-Sztainer, D. Adolescent consumption of sports and energy drinks: linkages to higher physical activity, unhealthy beverage patterns, cigarette smoking, and screen media use. J Nutr Educ Behav (2014) 46(3):181-7. doi:10.1016/j.jneb.2014.02.008

32. Cohen, J. A power primer. Psychol Bull (1992) 112(1):155-9. doi:10.1037// 0033-2909.112.1.15510.1037/0033-2909.112.1.155

33. Brooks, F, Klemera, E, Chester, K, Magnusson, J, and Spencer, N. HBSC england national report: findings from the 2018 HBSC study for england. Hatfield, England: University of Hertfordshire (2020) Available from: http://hbscengland.org/wpcontent/uploads/2020/01/HBSC-England-National-Report-2020.pdf (Accessed July 16,2020 ).

34. Visram, S, Crossley, SJ, Cheetham, M, and Lake, A. Children and young people's perceptions of energy drinks: a qualitative study. PLoS ONE (2017) 12 (11): e0188668. doi:10.1371/journal.pone.0188668

35. Vellonen, M, Konu, A, Kivimäki, H, Koivisto, A-M, and Joronen, K. Lukiolaisten ja ammattiin opiskelevien liikunta ja syömistottumusten yhteys ruutuaikaan [Associations between physical activity and eating habits with screen time among students in upper secondary schools and vocational schools]. Sosiaaliläketieteellinen Aikakauslehti [Journal Soc Medicine] (2015) 52(1). https://journal.fi/sla/article/view/50758 (Accessed February 11, 2020).

36. Costa, BM, Hayley, A, and Miller, P. Young adolescents' perceptions, patterns, and contexts of energy drink use. A focus group study. Appetite (2014) 80: 183-9. doi:10.1016/j.appet.2014.05.013

37. Kumar, G, Park, S, and Onufrak, S. Perceptions about energy drinks are associated with energy drink intake among U.S. Youth. Am J Health Promot (2015) 29(4):238-44. doi:10.4278/ajhp.130820-QUAN-435

38. Hagquist, CEI. Health inequalities among adolescents--the impact of academic orientation and parents' education. Eur J Public Health (2006) 17(1):21-6. doi:10.1093/eurpub/ckl087

39. Ruokolainen, O, and Mäki, N. Socioeducational status and substance use among adolescence: the differences between students in upper secondary vocational education and students in general upper secondary education. J Soc Med (2015) 52:47-59. doi:10.1093/eurpub/ckz011

40. THL. Kouluterveyskyselyn tuloksia. [School Health Promotion Study; online study results via Electronic reporting system]. (2018) Available from: https://thl. fi/fi/web/lapset-nuoret-ja-perheet/tutkimustuloksia (Accessed December 2, 2020).

41. Poulain, T, Vogel, M, Sobek, C, Hilbert, A, Körner, A, and Kiess, W. Associations between socio-economic status and child health: findings of a large German cohort study. Int J Environ Res Public Health (2019) 16(5):677. doi:10.3390/ijerph16050677

42. Carroll, HA., Heleniak, C, Witkiewitz, K, Lewis, M, Eakins, ME., Staples, J, et al. Effects of parental monitoring on alcohol use in the US and Sweden: a brief report. Addict Behaviors (2016) 63:89-92. doi:10.1016/j.addbeh.2016.07. 01410.1016/j.addbeh.2016.07.014

Copyright $\odot 2021$ Puupponen, Tynjälä, Tolvanen, Välimaa and Paakkari. This is an open-access article distributed under the terms of the Creative Commons Attribution License (CC BY). The use, distribution or reproduction in other forums is permitted, provided the original author(s) and the copyright owner(s) are credited and that the original publication in this journal is cited, in accordance with accepted academic practice. No use, distribution or reproduction is permitted which does not comply with these terms. 